\title{
A CONTRADIÇÃO PERFORMATIVA NA LUTA ESTRATÉGICA dOS MOVIMENTOS SOCIAIS POR RECONHECIMENTO EM UMA DEMOCRACIA CONSTITUCIONAL: 28 TESES DESCONSTRUTIVAS*
}

\author{
Daniel Oitaven Pearce Pamponet Miguel*
}

\section{RESUMO}

Este trabalho tem como objetivo geral propor um modelo deliberativo a ser adotado pelos movimentos sociais em sua luta por reconhecimento na forma de direitos humanos. A pesquisa é teórica, é qualitativa, utiliza o procedimento metodológico da análise de conteúdo bibliográfico e assume a desconstrução como matriz teórica. Concluímos que é possível compatibilizar o impulso emocional, conflituoso e honnethiano com a busca habermasiana pelo consenso, de modo que os movimentos sociais consigam evitar a incorrência na contradição performativa de, ao mesmo tempo, negarem estrategicamente o reconhecimento do outro e argumentarem com base nas ideias de democracia e alteridade.

Palavras-chave: movimentos sociais; reconhecimento de direitos; agir estratégico $\mathrm{X}$ agir comunicativo; contradição performativa; desconstrução e teoria crítica

\section{THE PERFORMATIVE CONTRADICTION IN SOCIAL MOVEMENTS' STRATEGIC STRUGGLE FOR RECOGNITION IN A CONSTITUTIONAL DEMOCRACY: 28 DECONSTRUCTIVE THESES}

\begin{abstract}
This work aims to create a deliberative model which can guide social movements in their struggles for recognition of human rights. This theoretical and qualitative research uses bibliographic content analysis as a methodological procedure and employs a deconstructive approach to its subject matter. We concluded it's possible to fit emotional impulses to struggle for recognition (Honneth) to respecting other participants in democratic debate (Habermas) in such a way that social movements manage to avoid performatively contradicting themselves when formulating recognitions claims based on the ideals of democracy and otherness.
\end{abstract}

Keywords: social movements; recognition of rights; strategic action X communicative action; performative contradiction; deconstruction and critical theory

\section{INTRODUÇÃO}

\footnotetext{
* Este texto é um produto do grupo de pesquisa "Direito, Justiça e cultura pop", liderado por seu autor e vinculado ao Programa de Pós-graduação stricto sensu em Direito da UFBa. E-mail: danieloitaven@hotmail.com

*** Doutor em Direito (UFBa), Doutor em Ciências Sociais (UFBa), mestre em Direito (UFBA), especialista em Fil. do Direito (PUC-MG) e graduado em Direito (UFBa). Ex-prof. adjunto de "Teoria e Instituições Políticas" da Faculdade de Filosofia da UFBa. Prof. adjunto de "Direito e Movimentos Sociais", "Hermenêutica", "Argumentação", "Teoria do Direito" e "Fil. do Direito" da graduação em Direito da UFBa. Professor permanente do Programa de Pós-graduação stricto sensu (Mestrado e Doutorado) em Direito da UFBa, no qual leciona "Teorias do Direito e da Justiça" e "Direito e Literatura". Prof. da Faculdade Baiana de Direito. Sócio do "Oitaven \& Pearce" (consultoria e litigância em hard cases).
} 
Este trabalho tem como objetivo geral apresentar, a partir de uma problematização desconstrutiva dos pensamentos de Habermas e Honneth, um modelo normativo dialógico adequado a orientar deliberativamente os movimentos sociais em sua luta por reconhecimento na forma de direitos humanos, de modo que não neguem estrategicamente o reconhecimento do outro com quem interagem na realização de seus pleitos. Seu problema de pesquisa é o seguinte: como se estruturaria um modelo normativo adequado a orientar deliberativamente os movimentos sociais em sua luta pelo reconhecimento na forma de direitos humanos?

A investigação justifica-se pelo fato de que a luta pelo reconhecimento dos direitos humanos não só é compatível com uma postura dialógica, como também a tem como imperativa. Ora, uma disposição deliberativa pode e deve ser exigida da atuação cidadã dos movimentos sociais em uma democracia constitucional, sob pena de totalitarismo moral em tempos de pluralismo axiológico, bem como de esvaziamento da própria base filosófica da ação transformadora dos movimentos sociais. Em outras palavras, o discurso de reconhecimento sustentado pelos movimentos sociais encontra fundamentos na necessidade de uma abertura de alter ao seu outro (ego), mas eventuais atitudes estratégicas desprovidas de disposição deliberativa revelam uma verticalização do representante de ego perante alter. Explicando de outro modo: a urgência por dar vazão às frustrações geradas por experiências de desrespeito, transmudando os respectivos sentimentos em reparações de injustiças sofridas, às vezes resulta em uma negação estratégica de reconhecimento do outro perante o qual os movimentos sociais pleiteiam o reconhecimento de $e g o$, o que configura uma contradição performativa ${ }^{12}$.

\footnotetext{
${ }^{1}$ A ideia de "contradição performativa" assumida por Habermas tem origem em Apel (1987) e consiste em uma contradição entre o conteúdo proposicional de um ato de fala e os pressupostos argumentativos assumidos por quem o pratica: "[...] contradição em que se envolve quem nega a possibilidade da racionalidade comunicativa. Essa contradição surge porque o que nega está sempre atribuindo validade para seus proferimentos, validade que é impensável sem o conceito de racionalidade comunicativa. Ou seja, ele nega a validade que é ao mesmo tempo pressuposta por ele em sua fala. [...]. O termo performativo se refere aqui aos pressupostos comunicativos (ou pragmáticos) necessários de todo ato de fala. Todo ato de fala se constitui de dois componentes básicos. Um é o conteúdo proposicional [...], que nas teorias dos atos de fala é chamado de componente locucionário. O segundo elemento, que contém o sentido comunicativo ou performativo do ato de fala, é chamado ilocucionário. Fazem parte dele todas as pretensões de validade associadas ao componente locucionário e todas as condições necessárias para que essas pretensões possam ser erguidas e cumpridas. Se o conteúdo proposicional contém "o que é dito", o componente ilocucionário se refere ao "como é dito" ou "o que é feito com o que é dito", ou seja, ao sentido comunicativo do ato de fala, às relações interpessoais que se constituem pelo reconhecimento das pretensões de validade erguidas com o ato de fala. A contradição performativa pode ser descrita, então, como uma contradição entre o que é dito e o como é dito. No caso em que a pretensão de validade é discutida, isto é, argumentada, há também uma série de pressuposições pragmáticas, constituídas pelos procedimentos da argumentação, do discurso. Assim, se alguém realmente duvida da existência desses procedimentos e argumenta contra eles ou contra a reconstrução deles, está pressupondo o que nega em sua fala argumentativa" (REPA in NOBRE, p. 295).

${ }^{2}$ Um exemplo dessa contradição performativa ocorreu na audiência pública realizada pelo STF para abrir espaço à pluralidade axiológica e interpretativa a respeito do aborto de fetos anencefálicos (ADPF n. 54-8/DF). Vejamos
} 


\title{
A pesquisa é teórica, é qualitativa, utiliza o procedimento metodológico da análise
}

\author{
de conteúdo bibliográfico, assume uma matriz teórica desconstrutiva de inspiração
}

derridariana (DERRIDA, 1991; BANKOVSKY, 2012; THOMASSEN, 2008) e elege como

cerne de seu referencial teórico: 1) de um lado, uma inspiração habermasiana quanto à necessidade de seguimento das regras intrínsecas à ação comunicativa voltada ao consenso, de modo que os movimentos sociais não desconsiderem seus interlocutores como tais, o que significaria incorrer em uma contradição performativa quando se está a lutar por reconhecimento com fundamento nas ideias de democracia, direitos humanos e alteridade; e 2)

um trecho da fala de Lia Zanotta Machado, antropóloga e professora da UNB, que compareceu à audiência perante os ministros do STF como representante da "Rede Nacional Feminista de Saúde, Direitos Sexuais e Direitos Reprodutivos": "Não vou falar aqui sobre a defesa em geral do direito de decidir ou da urgência da redução da mortalidade materna; venho trazer os rostos e os sentimentos das mulheres que se defrontam com uma gravidez com diagnóstico de anencefalia fetal. Baseio-me nos depoimentos de 58 mulheres que, graças à liminar do STF, decidiram interromper a gravidez. Suas experiências evidenciam três momentos: o do encontro com o trágico, com a tortura e com a supressão da tortura. Nomeiam a tragédia de diferentes formas. Érica relata o momento do diagnóstico com ultra-som: 'ele olhou para mim e disse que a criança tinha um problema. Perguntei se tinha solução. Não tinha. Depois, um crente, nas clínicas, me falou que Deus ia pôr um cérebro no filho na hora do nascimento.' Tomada pelo choro, responde a si mesma com angústia, mas com certeza: 'nunca que ia ocorrer que, depois de o nenê estar formado, fosse aparecer o cérebro do nada'. Essas vozes falam por si da importância da defesa, da dignidade e da liberdade dessas mulheres. O STF deve - um ponto de vista das mulheres que defendem há muito tempo os direitos das mulheres - olhar com particular atenção essas mulheres que estão passando por um sofrimento absolutamente desnecessário, dada a tragédia inevitável da anencefalia." (STF, 2008, p. 47-8; 58). O caráter estratégico da fala da professora fica patente devido à ridicularização de uma posição de base religiosa. Ora, sabe-se que as instituições religiosas cristãs costumam firmar posição inegociável contra a realização do aborto. A fala da gestante de feto anencefálico chamada Érica, a pretexto de ilustrar as experiências de sofrimento das mulheres que se encontram em situação semelhante, foi usada para atacar o discurso religioso. Seria perfeitamente possível defender, com base em evidências científicas sobre a impossibilidade de cura da anencefalia, o mesmo ponto de vista sem a menção "parabólica" ao diálogo entre o "crente" e Érica. Porém, a professora, não satisfeita, exibiu um documentário em que Érica veicula novamente o conteúdo do diálogo com o "crente". A postura discursiva da representante da rede feminista é incompatível com a postulação do reconhecimento da particularidade do Outro. O movimento social parece ignorar o Outro religioso por o enxergar como um mero obstáculo ao sucesso de sua luta por reconhecimento. Provavelmente o primeiro argumento que viria à mente para legitimar essa postura estratégica seria o de que o discurso religioso contra o aborto, dado pressupor a obediência a dogmas, é intolerante, moralmente totalitário e estratégico. A uma luta estratégica para institucionalizar uma concepção religiosa e unidimensional de vida boa, pois, se reagiria estrategicamente. Porém, esse argumento não é compatível com o próprio fundamento que embasa aquela luta por reconhecimento. Ora, é contraditório defender um olhar particularizado perante "as vozes, os rostos e os sentimentos das mulheres" e materializar tal defesa por meio de uma ação que ignora aquele com quem se interage. A fundamentação dos pleitos da rede feminista assume como premissa a necessidade de que o STF se abra ao ponto de vista das vítimas de gravidez de feto anencefálico, de modo a lhes dar um tratamento peculiar devido a tal circunstância trágica, mas incorre em uma contradição performativa ao adotar uma atitude beligerante e intolerante perante o outro Outro, menosprezando as pretensões morais dos "crentes". Essa indiferença às pretensões morais alheias fica ainda mais clara quando analisamos outro trecho da fala de Lia Machado, em que, ao abordar as liminares conquistadas por diversas mulheres em ações judiciais nas quais os magistrados expediram alvará autorizando a realização do aborto de feto anencefálico, a professora afirma não enxergar "alguma coisa que tenha sequer bens jurídicos a ponderar" (STF, 2008, p. 68). Mais uma vez, a representante da rede feminista desconsiderou a concepção religiosa alheia e desrespeitou a perspectiva hermenêutica de quem, com ou sem recurso a uma fundamentação religiosa, acredita que a vida de um feto anencefálico deve ser reconhecida como um bem jurídico tutelado e, pois, preservada pelo máximo de tempo possível. Há uma postura de arrogância na fala da representante do movimento social, a qual trata uma questão sensível e ideologicamente controversa como se fosse de óbvia resolução. 
de outro, uma inspiração na relação descrita por Honneth entre o desrespeito moral e a luta social por reconhecimento a explicação dos impulsos contestatórios resultantes das expectativas normativas que são consideradas violadas pelas vítimas de desrespeito social.

Podemos sintetizar nos seguintes itens os objetivos específicos da presente pesquisa: (1) cotejar desconstrutivamente, com base em Young, Benhabib e Fraser, autoras vinculadas à tradição crítica, as teorias de Habermas e Honneth; (2) desconstruir, com base nos teóricos desconstrutivistas Bankovsky e Thomassen, conceitos essenciais de Habermas e Honneth e, de modo correlato, a suposta oposição entre ambos; (3) aplicar criticamente a distinção habermasiana entre os usos comunicativo e estratégico da linguagem à postura deliberativa dos movimentos sociais em suas lutas por reconhecimento; (4) desconstruir a radicalidade das dicotomias agir comunicativo/agir estratégico, consenso/conflito, razão/retórica e convencimento/persuasão; (5) caracterizar a existência de um inexorável resquício perlocucionário em toda tentativa de ação comunicativa e em toda luta por reconhecimento; e (6) demonstrar como o telos da comunicação voltada para o entendimento pode encontrar um complemento na sensibilidade perante o Outro.

A estrutura deste trabalho é pouco comum: suas ideias serão expostas na forma de 28 teses divididas em quatro grupos. Iniciemos agora a exposição dessas teses.

\section{UMA LEITURA DESCONSTRUTIVA DE HABERMAS E HONNETH: ITERAÇÕES NA TEORIA CRÍTICA NO CONTEXTO DE UMA BRIGA DE FAMÍLIA}

1) Honneth está mais próximo de Habermas do que parece. Boa parte das críticas honnethianas às teses habermasianas, em verdade, resulta muito menos em alterações radicais do projeto crítico do que em iterações do pensamento de Habermas geradas pelo esforço de revisibilidade intrínseca a qualquer teoria construtiva da justiça.

(a) Honneth equivoca-se ao dizer que falta a Habermas caracterizar o sentimento de pertença a uma comunidade de interdependência como algo que surge a partir do compartilhamento de experiências de tarefas, ônus e sofrimentos relacionados a metas coletivas. Ora, a relevância atribuída por Habermas aos sentimentos morais de desrespeito permite que os vinculemos tanto ao influxo para a argumentação moral quanto ao elemento que gera o vínculo de interdependência entre sujeitos vulneráveis (solidariedade).

(b) Habermas (2004, p. 272-4; 307) confere relevância aos sentimentos gerados por violações daquilo que entendemos como pretensões normativas mesmo previamente à 
existência de sanções imputadas a tais violações, já que, em verdade, o que caracteriza uma violação como tal é o desrespeito àquilo a que o sujeito já considera fazer jus normativamente em seu contexto de vida. Ademais, Habermas afirma que os sentimentos morais podem cumprir um papel constitutivo para as confrontações morais em um modelo cognitivista. As tomadas de posição, nesse aspecto, têm duas dimensões, visto englobarem tanto a fundamentação racional no que diz respeito à correção ou não dos enunciados quanto uma reação afetiva diante de um comportamento que se avalia como correto ou não. Os sentimentos têm um conteúdo proposicional que acompanha a apreciação moral do comportamento, o que significa que podem ser compreendidos como juízos implícitos.

(c) Assim como o projeto habermasiano pretende cumprir a tarefa hegeliana de crítica ao universalismo abstrato e ao particularismo concreto por meios kantianos, Honneth está preocupado em cumprir as tarefas kantianas referentes à liberdade com meios hegelianos, motivo pelo qual procura uma concepção de vida boa que seja tímida o suficiente para manter o espaço da imparcialidade e do pluralismo kantianos. Não há, pois, uma oposição entre um Habermas kantiano e um Honneth hegeliano, mas, sim, dois autores que realizaram opções metodológicas distintas para fins de cumprimento de projetos políticos um tanto semelhantes, identificados simultaneamente, de um lado, com as tradições do hegelianismo de esquerda, e do outro, com a imparcialidade e o pluralismo axiológico. Se Honneth, pois, após optar metodologicamente por Hegel, fala em uma concepção formal de eticidade (o que poderia, em alguma medida, ser traduzido como uma concepção imparcial e pluralista de vida boa), talvez pudéssemos dizer que encontramos em Habermas, devido a sua opção metodológica, uma "concepção ética de formalismo", o que, em alguma medida, nos parece ser sugerido pela ideia habermasiana de que a linguagem tem o entendimento como telos. Podemos, nesse ponto, notar que Honneth, ao abordar a relação entre o social (descritivo) e o normativo, entre uma teoria social e uma teoria normativa da justiça, menciona um círculo hermenêutico (HONNETH, 2004, p. 390). Parece-nos que o referido modelo de circularidade hermenêutica, em alguma medida, pode também se aplicar ao telos da linguagem habermasiano quando o autor, parecendo buscar tal elemento teleológico no próprio mundo da vida, afirma que o saber sobre princípios está neste infiltrado, não permitindo que as convicções axiológicas concretas fiquem incólumes a sua abstração (HABERMAS, 2004, p. 310).

(d) Quando Honneth afirma que a solidariedade precisa envolver um traço particularista presente no desenvolvimento de qualquer comunidade social, dado que os seus 
membros estão sempre de acordo quanto a metas particulares eticamente definidas e, portanto, assumem de maneira compartilhada encargos específicos; parece haver um paralelo para tal noção na ideia habermasiana de patriotismo constitucional (HABERMAS, 2004, p. 240 e ss), complemento à constatação do próprio Habermas de que a justificação das normas exige uma sensibilidade empática de cada pessoa em relação a todos os outros, sendo necessária a integração entre cognição e disposição emocional. Quando notamos que o compromisso com as normas da ética do discurso impõe uma fidelidade afetiva aos princípios constitucionais, às instituições e às práticas democráticas que possibilitam um projeto consociativo em busca do entendimento mútuo, podemos estabelecer um paralelo com uma combinação entre fundamentação racional e reação afetiva em uma circularidade iterativa entre, de um lado, a avaliação da correção das normas e condutas, e, do outro, o cumprimento das normas que se considera como corretas. De tal maneira, os sentimentos, como juízos implícitos, servem como um impulso de integração política idôneo a colaborar para que se evite o problema do déficit motivacional gerado pela inexistência de um mandamento de integração ética. Tal impulso, porém, é necessário, mas não suficiente, dado que a afetividade que anima o agir também envolve os sentimentos de desrespeito destacados por Honneth. A tal respeito, devemos destacar que as iterações a respeito do sentido dos princípios constitucionais também entram em circularidade com os influxos éticos do mundo da vida e os sentimentos de desrespeito, e é justamente nesse processo que se faz necessário o esforço racional para que se evite a transmudação dos sentimentos em um impulso para a busca da integração ética. Portanto, os sentimentos de desrespeito que induzem ao recurso aos princípios de reconhecimento de Honneth, combinados à fidelidade afetiva aos princípios constitucionais habermasianos, podem catalisar o impulso por iterações que buscam a perfectibilização de uma justiça sempre por-vir.

2) Embora Habermas não dialogue diretamente com a maior parte da literatura tradicional sobre os movimentos sociais, e a despeito de Honneth (2003, p. 257) criticar as teorias dos movimentos sociais que ele chama de utilitaristas, traços das principais vertentes sobre o tema estão presentes nos pensamentos de ambos, que, com eventual diferença de ênfase: reconhecem que as tensões sociais (destacadas pelas teorias dos comportamentos coletivos) servem como impulso para a articulação dos movimentos sociais; destacam, como fazem as teorias dos novos movimentos sociais, a necessidade de uma postura crítica, reflexiva, orientada para a autonomia individual, para a prática de ações socialmente transformadoras e para os direitos humanos; admitem que a capacidade de um movimento social de se articular 
como tal e ter sucesso em suas lutas depende da existência de um contexto político favorável, como o de "ondas de controvérsia" (teorias das oportunidades políticas), e do sucesso de suas estratégias organizacionais (teorias da mobilização de recursos); e reconhecem à transformação normativa projetada na linguagem dos "frames" um expediente de catalisação das ressignificações dos direitos humanos praticadas pelos movimentos sociais em suas ações na esfera pública.

3) A relação estabelecida por Douzinas (2009, p. 265 e ss.) entre, de um lado, direitos humanos e utopia, e do outro, direitos humanos e democracia, demonstra como uma abordagem desconstrutiva sobre a luta por reconhecimento desenvolvida pelos movimentos sociais pode conservar um potencial construtivo. A noção de "vôo de sentido" pode facilmente ser relacionada à articulação de semânticas coletivas intrínseca à atuação conflitiva de tais movimentos, conforme destacado por Honneth (2003, p. 258 e ss.) Ademais, se tais vôos são desenvolvidos no âmbito da esfera pública, é verdade também que precisam ser submetidos, em um Estado Democrático de Direito, aos procedimentos democráticos de institucionalização normativa, o que, nos moldes da pretensão habermasiana de superação de teorias democráticas que restringem as decisões políticas à aplicação da regra da maioria, exige a assunção de um modelo de razão comunicativa a permear tanto os debates realizados no mundo da vida quanto as tomadas de posição no âmbito das decisões políticas. Há, aí, uma circularidade iterativa, dado que, por um lado, as condições de participação livre e igual nas decisões políticas são um pressuposto para que estas possam ser efetivamente consideradas democráticas; mas, por outro, a própria atribuição expansiva de novos sentidos à expressão "direitos humanos" amplia, em sentido amplo, a própria noção do que podemos chamar de "direitos políticos" em sentido lato, os quais podem, então, ser entendidos como todos aqueles que garantem, efetivam e/ou expandem a abrangência do princípio da paridade de participação (FRASER, 2008, p. 119)

4) O surgimento de "frames" componentes das semânticas coletivas dos movimentos sociais pode ser relacionado, honnethianamente, à relação entre sentimentos de desrespeito, articulação e lutas por reconhecimento, e, com o Habermas maduro, à combinação entre aspectos racionais e sentimentos morais na realização de juízos de correção.

\section{A CONTRADIÇÃO PERFORMATIVA NA LUTA ESTRATÉGICA DOS MOVIMENTOS SOCIAIS POR RECONHECIMENTO}

5) Os movimentos sociais, às vezes, combinam uma estratégia de polarização de teses 
à ideia de que a pretensão moral que estão a defender é, desde antes do início do processo deliberativo, correta e justa, devendo, portanto, necessariamente ser acolhida, independentemente dos argumentos que possam ser expostos pelos demais participantes da interação. Trata-se de postura que, em alguma medida, se vincula ao que Fraser (in FRASER; HONNETH, 2003, p. 12) chamou de "essencialismo estratégico", postura identitária que tende a assumir como "metafísico" o caráter justo dos pleitos realizados, o que tornaria justificável a corrupção da linguagem e das relações de confiança estabelecidas no jogo de linguagem da democracia, tendo em vista o objetivo a ser cumprido, qual seja, o de institucionalizar dadas pretensões morais. O referido "essencialismo estratégico", frequentemente, busca estabelecer, unidimensionalmente, um "consenso" previamente à deliberação, de modo a qualificar como irrelevantes ou ridículas orientações e resultados que ofendam as pretensões morais de caráter "metafísico" sustentadas pelos movimentos sociais, o que limita o feixe de razões efetivamente consideradas no processo deliberativo. Os "frames" dominantes (CALVERT; WARREN, 2012, p. 15), com frequência, produzem um efeito de "audição seletiva" na opinião pública, o que resulta, em uma combinação com a estratégia de polarização e de construção de estereótipos grupais positivos e negativas, no estabelecimento de diretrizes linguísticas compatíveis com a semântica coletiva dos movimentos sociais, marginalizando qualquer tipo de posicionamento contraposto à "verdade essencialista", mesmo quando esta não é oriunda dos grupos adversários e/ou não é defendida de modo estratégico. Os "frames" dominantes, pois, restringem a liberdade dos agentes no que diz respeito à aceitação ou não de pretensões, já que as razões não são mais tão importantes, visto que a "qualidade metafísica" da pretensão é suficiente para a tornar digna de acolhimento. O resultado de tal processo é a transposição dos rótulos integrantes da semântica coletiva dos movimentos sociais para sujeitos que não têm qualquer vinculação com os grupos adversários dos movimentos - muitas vezes se baseando, inclusive, em fundamentos completamente distintos daquelas utilizadas pelos ditos adversários - meramente pelo fato de tais sujeitos se "atreverem" a questionar os "frames" dominantes.

6) A confusão entre o que é vivenciado como uma injustiça e o que deve ser considerado injusto costuma ser usada como pretexto para que os movimentos sociais confiram a si mesmos a autoridade para a determinação unilateral do que é injusto e do que é preconceituoso por parte do Outro. Constitui-se, assim, um "frame baseado em grupo" (CALVERT; WARREN, p. 16) que estabelece um estereótipo positivo dos membros de movimentos sociais e daqueles por eles defendidos, de modo que a suposta negação de 
reconhecimento seja convertida em uma impossibilidade de questionamento de suas pretensões. Nesse ponto, argumentos derridarianos, como o da "impossibilidade de se compreender através da diferença", são utilizados não como uma admissão do falibilismo intrínseco ao consenso idônea a estimular uma abertura contínua ao Outro e um enriquecimento deliberativo, mas, sim, paradoxalmente, para que se encerre categoricamente a discussão em favor da posição autoritativamente estabelecida pelo movimento social, cristalizada em "frames dominantes" e vinculada a arranjos polarizadores. Contudo, entendemos, à la Derrida, que a obrigação ética de cuidado perante o Outro enseja em contrapartida, a responsabilidade perante todos os Outros de uma decisão sobre a justiça que sempre se caracteriza pela indecidibilidade, não podendo, portanto, ser "metafisicamente" antecipada, desconsiderando-se a posição alheia. Concordamos com Fraser (in FRASER; HONNETH, 2003, p. 205) que o fato de se sentir como vítima/ injustiçado/psicologicamente fragilizado, pois, não autoriza um sujeito individual ou coletivo a converter automática e unilateralmente essa experiência psicológica em uma fonte decisória absoluta a respeito de decisões políticas sobre pleitos de reconhecimento. É nesse ponto, porém, que os "frames" problemáticos obscurecem a necessidade de se fazer tal ressalva, visto fecharem antecipadamente a possibilidade de problematização das reivindicações "multiculturalistas mainstream" (Fraser), convertendo as semânticas coletivas usadas pelos movimentos sociais em um passe livre, de maneira que a voz daqueles que se afirmam injustiçados se converta em autoritativa pelo seu mero "pedigree", ou seja, pela mera origem em sujeitos coletivos que se anunciam como vítimas de desrespeito.

7) Os movimentos sociais não deveriam justificar com base nos sentimentos morais de desrespeito e na suposta e presumida atuação estratégica de seus interlocutores uma espécie de contra-ataque estratégico, pois isso implica a incorrência em uma contradição performativa. A contradição surge quando os movimentos apelam estrategicamente, mesmo que sem remissão a teóricos, aos direitos humanos e essenciais constitucionais, a direitos fundamentais constitucionalmente positivados e interesses generalizáveis, ao princípio recognitivo de igualdade de direitos, à paridade participativa e à tentativa de compreensão do outro através da diferença, dado que todos esses elementos, como se pode depreender, respectivamente, da leitura das obras de Benhabib, Habermas, Honneth, Fraser e Young, são compreendidos como intrínsecos às suas próprias concepções de democracia. Ora, se os movimentos sociais querem a democracia, precisam recepcioná-la como um todo, não sendo admissível que a utilizem como uma mera referência argumentativa instrumentalizada por um discurso estratégico. 
8) Os movimentos sociais, quando, no contexto do debate público, recorrem a vôos de sentido a partir das noções de democracia e seus respectivos universais, aderem performativamente às regras de seu jogo de linguagem, o que significa não poderem pretender, iterativamente, corrompê-las radicalmente por dentro, sob pena da prática de uma contradição performativa. Ora, as regras do jogo de linguagem democrático, em respeito à historicidade dos sentidos dos universais interpretados, fecham as portas para que a indecidibilidade e o resquício de violência sempre presentes nas iterações sejam convertidos em arbitrariedade.

9) Os movimentos sociais, ao apelarem para um olhar ao Outro, se comprometem em respeitá-lo, e, ao fundamentarem suas lutas nas experiências e sentimentos de desrespeito, se comprometem a não gerar esse tipo de sentimento em seus interlocutores. Porém, quando desenvolvem suas lutas por reconhecimento estrategicamente, quebram performativamente tais compromissos, visto negarem o reconhecimento do outro como interlocutor e, assim, gerarem no Outro sentimentos de desrespeito, fragilizando suas desde sempre vulneráveis estruturas de personalidade. Para os movimentos sociais que agem assim, é como se existissem alteridades mais ou menos valiosas, sendo possível, em nome daquelas, a instrumentalização destas.

10) Os movimentos sociais, ao praticarem a supracitada contradição performativa, não realizam vôos de sentido que pretendam questionar o sentido da democracia por dentro, motivo pelo qual se mantêm vinculados aos compromissos linguísticos evocados quando remetem à própria democracia e aos seus universais. A nossa crítica não tem, pois, como objeto os movimentos que buscam, manifestamente, protestar contra injustiças e questionar iterativamente, de um ponto de vista externo ao ambiente deliberativo, ainda que interior ao sistema democrático, os sentidos da democracia e dos essenciais constitucionais. $\mathrm{O}$ agir estratégico que estamos a criticar diz respeito ao recurso, no contexto argumentativo de uma deliberação, à democracia e aos universais a ela vinculadas como "aliados", usando-os como fundamento para os seus pleitos de reconhecimento do Outro, mas, ao mesmo tempo, agindo insidiosamente contra os compromissos linguísticos evocados pela própria democracia e pelos próprios universais. Os movimentos vinculam-se a um "frame" de alteridade, o que os faz assumir um compromisso de respeitar o Outro como interlocutor, mas ofendem performativamente esse mesmo "frame" ao desconsiderarem as razões daqueles com quem "interagem". Assim, praticam uma "autoexclusão" ao atentarem contra a democracia, visto que não estão a realizar iterações, com o propósito de questionamento do sentido da democracia, e sim a se vincular a compromissos com o sentido histórico de democracia nos termos do jogo de 
linguagem dominante, quebrando, contudo, estrategicamente, tais compromissos.

11) A prática de contradições performativas pelos movimentos sociais, tanto por inviabilidade fática quanto por razões teóricas, não pode ensejar uma exclusão ou limitação do discurso estratégico do espaço deliberativo de maneira coercitiva. Quando consideramos que os movimentos estão "se excluindo", não atrelamos tal premissa à ideia habermasiana de que discursos contrários à democracia devem ser vetados, pois, como visto, os movimentos não atacam a democracia; ao contrário, eles a assumem como premissa atrelada ao "frame da alteridade", mas a subvertem em sua prática de contradição performativa. O discurso de tais movimentos assume o Estado Democrático de Direito como inegociável, embora o contradiga na prática, algo que não pode e não deve ser resolvido mediante qualquer tipo de medida intolerante em nome de uma proteção da democracia, mas apenas pela via de uma provocação à autorreflexividade dos movimentos sociais tal qual a realizada por este trabalho, que se pretende uma ação de um filósofo-cidadão. É justamente pelo caráter inegociável da democracia no discurso dos movimentos sociais aqui criticados que os consideramos vinculados aos compromissos intrínsecos ao jogo de linguagem da democracia deliberativa, precisando respeitá-los ao praticarem vôos de sentido em suas lutas por reconhecimento.

12) Em uma leitura desconstrutiva, Honneth (2008, p. 77) pode contribuir para a nossa crítica ao agir estratégico dos movimentos, visto que ele adverte sobre a possibilidade de que experiências de desrespeito compartilhadas estimulem o surgimento de coletividades que convertam seus sentimentos em atos de violência. Ora, o agir estratégico dos movimentos, ainda que não caracterize uma violência física, é uma violência à dignidade de seus interlocutores como merecedores de igual consideração, motivo pelo qual, mutatis mutandis, a advertência do autor sobre o uso dos sentimentos de desrespeito como pretexto para a adoção de uma postura violenta faz-se aqui pertinente. Não seria, pois, incompatível com as lições de Honneth, após uma leitura desconstrutiva, a afirmação de que é nocivo à democracia que os "frames" sejam recebidos passivamente, sem questionamentos (CALVERT; WARREN, p. 8), meramente pelo fato de serem utilizados por aqueles que se autodeclaram como vítimas de desrespeito, pois esse tipo de recepção envolve uma interferência do sentimento de compaixão perante o pretenso oprimido no momento da cognição, o que resulta em manipulação emocional.

13) Diferentemente do que os movimentos sociais podem argumentar, não importa quem começou a agir estrategicamente, pois a ação estratégica dos movimentos, mesmo 
quando reativa, esvazia o sentido do próprio fundamento para os seus pleitos de justiça, o que significa contribuir para um aprofundamento das injustiças mediante o empobrecimento da qualidade da deliberação democrática. Buscamos fundamento para tal conjetura em Habermas (1984, I, p. 287), para quem, segundo interpretação de Martineau e Kaurloto (2020, p. 3), o agir estratégico sub-reptício gera resultados irracionais ao estimular uma contínua luta desordenada pelo poder. Assumindo que o discurso dos direitos humanos pode motivar construtivamente uma perfectibilização da justiça, mas também gerar uma fragilização do processo democrático de institucionalização de conteúdos jurídico-positivos, entendemos que o referido agir estratégico bloqueia o futuro. Os movimentos sociais, articuladores de uma semântica coletiva motivados pelos sentimentos oriundos de experiências de desrespeito, incorrem em uma contradição performativa se, como resultado de suas lutas por reconhecimento, progridem no progresso da marginalização da coletividade que defendem e conseguem estabelecer "frames" dominantes, polarizadores e/ou "baseados em grupos", de maneira a subjugar os seus ditos adversários e fazer que eles se sintam menos dignos de reconhecimento, desprovidos de paridade participativa. A possibilidade de que os ditos adversários eventualmente pratiquem esforços de boa-fé não pode ser desconsiderada antecipadamente, não sendo adequado que os movimentos sociais presumam sempre que seus "opositores" estão adotando posturas, mesmo que subrepticiamente, estratégicas. Ora, mesmo nos casos em que o agir estratégico por parte dos ditos adversários se verifique, o papel dos movimentos sociais, como bem notou Habermas, é qualificar e difundir o poder comunicativo mediante um incremento da qualidade das deliberações públicas em uma democracia, entendida como por-vir e orientada por uma perfectibilização da justiça, possível apenas como impossível.

14) O fracasso inexorável do procedimento deliberativo ideal não pode servir de pretexto para que se ignore o dever de realização de um esforço contínuo no sentido de evitar ao máximo que a luta por reconhecimento ignore os outros Outros e, assim, seja performativamente contraditória com os seus próprios fundamentos. O participante de uma interação deve, desconstrutivamente, usar os sentimentos de desrespeito a suas particularidades como um impulso para o seu pleito de reconhecimento como digno perante aqueles com quem está a dialogar (conflituosidade honnethiana), mas, construtivamente, afastar-se ao máximo da tentação do agir estratégico ao argumentar (consensualidade habermasiana). 


\section{ENTRE A PERSUASIVIDADE CONFLITUOSA DA RETÓRICA E O CONVENCIMENTO CONSENSUAL DO DIÁLOGO: O INEXORÁVEL RESQUIÍCIO PERLOCUCIONÁRIO NA PRAGMÁTICA DA (IM)POSSIBILIDADE}

15) Os sentimentos de injustiça e desrespeito tornam viável o impulso narrativo de lutar por reconhecimento, enquanto os princípios de justiça de Honneth compõem o núcleo da linguagem normativa dos direitos humanos. Trata-se de uma mediação entre a obrigação perante o Outro único e a imparcialidade, sendo necessário, porém, que a atenção a esta última seja regida, para fins de conversão dos resultados deliberativos na linguagem dos princípios de justiça, por um procedimento deliberativo como o de Habermas. Nesse ponto, as contribuições do debate entre Benhabib e Young (1997a) quanto às dificuldades para se compreender através da diferença tornam patente a necessidade de que o modelo habermasiano de interação seja desconstrutivamente complementado, de maneira a: comportar, no momento de impulso para a luta por reconhecimento, a narratividade e a retórica como elementos intrínsecos ao processo de formulação de pretensões na linguagem da argumentação racional; e reconhecer as variações hermenêuticas intrínsecas à circularidade entre normatividade e narratividade (YOUNG, 1997b). Tal questão se torna ainda mais relevante no contexto de exposição de um novo tipo de pretensão, de difícil ou inviável recondução a princípios normativos já conhecidos, o que exige, como primeiro passo do Dito da deliberação, que se contem histórias sobre o tema até que se torne viável a articulação iterativa da respectiva pretensão, ainda particular e narrativa, na linguagem normativa de um universal - seja este chamado de "direitos humanos" (Benhabib), "paridade de participação (Fraser), "princípio recognitivo de igualdade" (Honneth) ou “interesses generalizáveis" (Habermas) - e esta possa ser aplicada, em moldes de repetição e alteração (iterações democráticas), às narrativas vindouras.

16) A consolidação de essenciais constitucionais, como ocorre com qualquer formulação de universais, envolve certa violência intrínseca - no caso, o ato de fundação constitucional (BENHABIB, 2004). Por outro lado, cada particular resultante da interpretação de tais universais também tem caráter violento, dado o caráter necessariamente modificador das iterações, compreendidas como repetição cum alteração. Consideramos que a tensão entre tais dimensões de violência e o esforço de racionalização que pode certamente ser praticado em tais atos de formulação de universais e materialização de particulares pode ser compreendida a partir de um paralelo com os dois âmbitos - o sentimental e o racional - identificados por 
Habermas em toda tomada de posição sobre questões morais. Nesse sentido, é compreensível a relevância conferida por Derrida à retórica, à persuasão e ao poder como o caráter afetivo da relação entre emissor e interlocutor, ou seja, uma dimensão persuasiva da comunicação, a qual está presente mesmo quando se realiza um esforço de racionalização da tomada de posição.

17) A responsabilidade que temos pela definição histórica da democracia e com o que é excluído por tal definição envolve uma consideração da versão atualizada do jogo de linguagem democrático, de maneira que a compreensão presente dos essenciais constitucionais - inclusive a liberdade de expressão, essencial para que não se pretenda calar os próprios movimentos sociais praticantes de um agir estratégico - fique protegida pela vinculação aos compromissos contra efeitos iterativos radicais (BENHABIB, 2004, p. 108 e ss.) - ainda que, obviamente, sempre haja um inexorável resquício iterativo em qualquer nova interpretação.

18) Uma tensão entre uso comunicativo e uso estratégico da linguagem, ou, em termos retóricos, entre a persuasão - cuja ênfase está não apenas na dimensão do ethos (ilocucionária), mas também na do pathos (perlocucionária) - e o convencimento - cujo destaque se encontra no logos - é intrínseca à prática dos atos de fala, visto que a postura perfeitamente voltada para o convencimento/uso comunicativo da linguagem é empiricamente implausível, ainda que seja exigível que a pretendamos conceitualmente possível, mesmo sabendo de sua impossibilidade conceitual. Ethos, pathos e logos, ou ilocução, perlocução e locução, estão, em alguma medida, sempre presentes no uso da linguagem, mesmo quando este se dá comunicativamente. Neste caso, porém, há uma prevalência da pretensão de convencimento sobre a de persuasão, o que entendemos ser equivalente, em Habermas (1984, I, p. 290), ao domínio dos efeitos ilocucionários (e locucionário) sobre os perlocucionários, típico da ação comunicativa. Entendemos, portanto, que não pode ser compreendida como rígida a distinção entre persuasão e convencimento (PERELMAN, 1996, p. 29-34). Ora, todo discurso que assume pretensões de convencimento o faz idealmente, mas sempre há ali um resquício persuasivo.

19) Entendemos desconstrutivamente que o Habermas maduro (1990, p. 306; 2002, p. 210 e ss.), ao admitir que a ação comunicativa exige a prática de atos ilocucionários sem reservas, mas comporta efeitos perlocucionários, desde que estes apareçam no discurso abertamente e suscetíveis ao consenso, permite-nos afirmar que existe sempre um elemento retórico-persuasivo na relação entre os participantes da interação. O que podemos exigir deles, portanto, é uma autovigilância quanto ao dever de preservar, no discurso, a predominância da obrigação ilocucionária sobre o sucesso perlocucionário. Trata-se de não permitir que a 
racionalidade comunicativa seja afastada em um grau que gere uma barreira ao poder vinculativo e associativo dos atos ilocucionários. Contra a dicotomização do Habermas de "Teoria da ação comunicativa" (1984, I), entendemos que sempre há uma dimensão perlocucionária nos atos de fala, mesmo quando o utente da linguagem consegue manter a dependência dos objetivos e efeitos perlocucionários em relação aos objetivos e efeitos ilocucionários. A tensão entre as pragmáticas da possibilidade e da impossibilidade de alcance perfeito do justo no procedimento discursivo (BANKOVSKY, 2012, p. 142) em Habermas envolve a percepção de que a inviabilidade de perfeita efetivação das condições ideais de fala implica não podermos falar em um agir totalmente orientado para o entendimento mútuo ou para a concordância em sentido estrito (acordo), mas apenas em uma aproximação, no máximo grau possível, ao uso comunicativo da linguagem. Sempre haverá um resquício estratégico, persuasivo, perlocucionário, conflituoso em toda tentativa de agir comunicativo, resquício que tem como impulso os juízos sentimentais implícitos na avaliação de pretensões morais mencionado pelo Habermas maduro - o que, no contexto da luta por reconhecimento dos movimentos sociais, envolve o impulso gerado pelos sentimentos de desrespeito.

20) A potencialidade intrínseca ao dizer que também é um fazer sempre guarda um resquício de persuasividade, afirmação compatível com a admissão pelo Habermas "maduro" de que aspectos sentimentais e racionais coexistem na realização de juízos morais. Os juízos emocionais implícitos sempre estarão presentes na realização de juízos sobre pretensões de validade, nunca podendo ser completamente afastados. O resquício de persuasividade está presente mesmo quando nos esforçamos por uma comunicação voltada para o entendimento. Transpondo tal raciocínio para a tensão entre agir comunicativo e agir estratégico, assumimos que a noção de telos da linguagem como voltado para o entendimento (HABERMAS, 2004, p. 9;108) não significa que haja uma tendência natural do homem ao agir comunicativo (ou ao desvelamento) a um agir "virtuoso". Entendemos, isso sim, a confiança na linguagem como algo que demanda a virtude da disposição para um esforço voltado ao entendimento mútuo.

Os sentimentos de desrespeito (ou, digamos, as inclinações kantianas) são elementos que contribuem para a tendência humana ao velamento, ou seja, uma atribuição de sentido irreflexiva. O impulso gerado pelas inclinações, pois, faria os movimentos sociais, motivados por seus sentimentos de desrespeito, apresentarem uma tendência ao agir estratégico (ou ao velamento), o que explica a dificuldade que eventualmente têm para agir de acordo com o jogo de linguagem da democracia deliberativa, o qual exige um esforço contrafático de autocontrole. 
Tendo como referência o "como hermenêutico", pode-se dizer que, em Heidegger (2005, p. 198; 280), a pré-estrutura da compreensão tende sempre ao velamento do ser e da verdade. A compreensão tende a alienar quem compreende, visto dar prevalência ao que já está (pré-)concebido em sua estrutura de compreender. Deve-se, pois, mediante um esforço autocompreensivo, escapar da própria essência auto-alienante, de modo a buscar a "coisa mesma" no fenômeno e desvelá-la. Essa é a postura de quem, sem negar a impossibilidade de um autocontrole total, tem consciência de seus impulsos e condição de decidir não os seguir. Tal ideia, compatível com o Habermas maduro e Honneth, move-nos a propor ao sujeito canalizar seus sentimentos de desrespeito como impulso para a luta por reconhecimento que evita uma inércia por falta de motivação moral para perseguir a justiça-por-vir, mas sem considerar esse impulso um passe livre para o agir estratégico, que, no contexto da argumentação pública, deve ser afastado ao máximo mediante um esforço de racionalização.

\section{UM MODELO DELIBERATIVO DE COMPREENSÃO ATRAVÉS DA DIFERENÇA}

21) Ser responsável é estar assimetricamente aberto e responder à alteridade do Outro. É verdade, porém, que a alteridade alheia escapa de nossa tentativa de apropriação. Ser responsável com o Outro, pois, é a tarefa apenas possível como impossível de responder ao Outro e a sua alteridade. Por sua vez, em Habermas, responder ao Outro, apresentando-lhe razões a respeito das pretensões de validade sustentadas, é algo que ocorre no contexto de um processo discursivo caracterizado pela reciprocidade, em que se busca dar ao Outro aquilo que lhe é devido. De todo modo, também em Habermas a alteridade do Outro escapa parcialmente da nossa resposta - o que fica patente no caráter contrafático do modelo habermasiano de situação ideal de fala - o que torna impossível o cumprimento de nossa responsabilidade para com o Outro, ainda que, ao mesmo tempo, tal impossibilidade seja simultaneamente o que possibilita a responsabilidade ao impedir que esta seja exaurível em uma comunicação perfeita.

22) Podemos, orientados pelo caráter falibilista da obediência ao procedimento discursivo habermasiano (um modelo que só se concretiza aproximativamente) e inspirados pela ideia de Habermas de que a orientação ao agir comunicativo não envolve apenas deveres negativos de não enganar, mas também deveres positivos de reconhecimento do Outro como interlocutor; formular a intuição fundamental do modelo que estamos a propor: tendo em vista que só podemos compreender através da diferença e o inexorável resquício perlocucionário, persuasivo, emocional, estratégico, direcionado ao velamento, intrínseco a toda tentativa de 
ação comunicativa e a toda luta por reconhecimento; os participantes de uma interação deliberativa devem praticar atos de fala com o propósito de alcançar um perfeito entendimento mútuo, um desvelamento, mesmo sabendo que este, faticamente, sempre será imperfeito.

23) Aarnio (1991) considera viável a combinação entre um resquício persuasivo e a pretensão de convencimento típica da busca por um consenso racional, dado que a possibilidade de um acordo pressupõe um compartilhamento de uma forma de vida. Com base em tal premissa, e visto que Habermas enxerga nos discursos racionais uma função suplementar de sensibilização recíproca dos participantes para a compreensão que o Outro tem do mundo e de si mesmo; a percepção habermasiana de um elemento deôntico-teleológico intrínseca à linguagem, desconstrutivamente, pode fundamentar as pretensões de um diálogo através da diferença, consistindo em um convite ético-político performativo para o desenvolvimento de uma relação de amizade, simultaneamente compatível com as ideias de democracia-por-vir e de um impulso ético de preocupação com um Outro completamente não-representável.

24) Busca-se, diatopicamente e com as posturas derridarianas de humildade, abertura e resiliência, explicar como poderia se consolidar, a longo prazo, um terreno comum idôneo a, mesmo sem permitir uma inversão de perspectivas, possibilitar uma melhor compreensão através da diferença. Não há no projeto que aqui defendemos uma necessária orientação político-emancipatória, mas apenas um desiderato de aproximação subcultural, o que possibilitaria uma resolução conjunta de controvérsias que, hoje, ainda são tidas como intersubculturais. Lembrando Young, para quem a diferença, embora seja inexorável, não torna impossível a comunicação, podemos dizer que a dimensão perlocucionária da linguagem se referiria ao modo como o membro de uma cultura que não a do utente da linguagem receberia sua fala através da diferença, mormente quanto à pretensão persuasiva do falante - tal qual um Aquiles intersubcultural - orientada à redução perfectibilizante da incompreensibilidade.

25) Com Hendley (1996, p. 1), entendemos viável uma complementação entre a relação substantiva com o Outro (Levinas) e a dimensão procedimental da linguagem (Habermas), o que resultaria em uma abordagem do significado moral da linguagem como uma prática governada por regras que responde ao apelo da face do Outro. Ora, em Levinas, conversar implica conferir ao outro o direito de questionar o dito e de obter respostas justificadas resultantes de uma devida consideração de razões. Tanto em Levinas quanto em Habermas, pois, conversar significa envolver-se em uma racionalidade com implicações morais. Porém, a orientação moral implícita no discurso não pode ter sua articulação resumida 
a termos procedimentais, demandando uma análise fundada na forma de sensibilidade que nos move a cuidar do outro. Isso se torna perceptível quando analisamos os compromissos pressupostos em toda conversa, pois um diálogo compele a uma consideração incondicional do Outro, a qual transcende as próprias razões pelas quais os participantes da interação a iniciaram, dado que qualquer um deles pode incrementar a interação e problematizar essas mesmas razões, no que deverá ser prontamente respondido. Há, pois, compromissos incondicionais assumidos no discurso, os quais têm relevância moral no contexto da justificação de normas práticas, e o que constitui tal incondicionalidade é justamente a sensibilidade perante o rosto do Outro.

26) O apelo ao Outro deve ser entendido como um momento prévio de convite à constituição de um terreno comum, o qual possibilitaria, à medida em que se joga e edifica o novo jogo de linguagem, a perfectibilização de um sentido comum de justiça, regido pela tensão entre as pragmáticas da possibilidade e da impossibilidade de alcance perfeito do justo no procedimento discursivo. Encontramos no surgimento da responsabilidade ética perante o Outro em Levinas (1978, p. 55 e ss.) uma referência para a constituição do ponto de partida da interação entre sujeitos pertencentes a subculturas distintas, prévio mesmo ao ato persuasivo de convite ao diálogo intersubcultural. O convite persuasivo, portanto, é precedido por uma espécie de convite sensível, que se dá pelo momento em que nos deparamos com o rosto, constituindo-nos, assim, como selves. Porém, o ato perlocucionário por meio do qual lhe convidamos à união é indispensável à configuração mesma de uma forma de vida e um jogo de linguagem comuns, condições essenciais ao desenvolvimento de um diálogo intersubcultural.

Há espaço, portanto, tanto para, com Levinas, o "ser-afetado", que ultrapassa a possibilidade de reformulação do conteúdo da experiência ética perante o Outro, como, com Habermas, para o esforço de reformulação, ainda que imperfeita, desse momento. Por um lado, uma reformulação tal em sentido perfeito seria inviável à luz da distinção entre as dimensões hermenêutica e apofântica da linguagem ou mesmo ao considerarmos a inexorável imperfeição quanto à efetividade do ideal em Habermas - o momento sensível do ser-afetado, ao ser entendido pelo sujeito, fazendo deste o self por meio da percepção que tem do Outro, consiste em uma experiência linguística em sentido hermenêutico. Por outro lado, como entende Habermas, não é possível escutar sem reformular apofanticamente o conteúdo daquilo que se escuta - e essa reformulação pode se aplicar inclusive à compreensão de um eventual convite para escutar, que entendemos aqui como persuasivo. Mantém-se, assim, o compromisso 
compartilhado por Habermas, Honneth, Derrida, Young, Benhabib e Fraser com a justiça - e é a reformulação, ainda que imperfeita, do conteúdo do convite o que proporciona a compreensão deste convite e a potencial adesão do auditório convidado ao projeto de diálogo intersubcultural.

27) $\mathrm{O}$ momento imediatamente subsequente à aceitação do convite envolve, com Habermas, a busca por uma perspectiva compartilhada que atravesse as diferenças iniciais, o que nos parece compatível com a leitura da ética do discurso feita por Young. Os interesses morais tornar-se-iam compreensíveis nos termos de pressuposições pragmáticas paulatinamente compartilhadas, à luz da contrafactualidade intrínseca ao acordo universal habermasiano. Não é, portanto, como pensava Levinas, impossível o entendimento entre os sujeitos, ainda que, como entende Young, tal entendimento só possa se realizar através da diferença. Esse entendimento pressupõe um aprendizado recíproco contínuo - tal qual o de crianças perante a normatividade - a respeito dos jogos de linguagem alienígenas em que os participantes são jogados por meio do mútuo convite ao Outro.

28) Os atos perlocucionários, desde que não sejam parasitários, mas, sim, praticados em conformidade com o telos da linguagem e, portanto, dirigidos por metas ilocucionárias, não são incompatíveis, mas, sim, essenciais ao compromisso habermasiano com um procedimento discursivo, ainda que imperfeito. Falar diatopicamente pressupõe praticar persuasivamente, a partir de um contexto historicamente situado, modificações no mundo da vida que possibilitem uma compreensão através da diferença. Ora, o impulso para tal persuasão reside justamente nos sentimentos de desrespeito gerados pelo déficit de reconhecimento, o que motiva, honnethianamente, a luta dos movimentos sociais. E o próprio telos da linguagem em Habermas (a orientação para o acordo) parece encontrar semelhança na concepção de Panikkar (2006) do ser humano como um ser dialogal - homo loquens, para o qual o diálogo é constitutivo de si mesmo - que fala para entender os outros, entender a si mesmo e ser entendido pelos outros.

A sensibilidade como um momento anterior à persuasão e ao esforço em busca do consenso explica como os sentimentos de desrespeito e de cuidado com o Outro podem entrar em conflito. Devemos ter em mente que o impulso de cuidado, como percebe o próprio Honneth, é ambíguo, visto que, embora catapulte a busca pelo cumprimento da obrigação ética perante o Outro concreto, se transportado para o âmbito da deliberação, ameaça o mandamento de imparcialidade necessariamente vinculado ao princípio recognitivo da igualdade de direitos. 
Dado que, como reconhece o próprio Habermas, certa dimensão emocional sempre estará envolvida, na forma de juízos implícitos, nas tomadas de posição, a questão está em como lidar com os impulsos sensíveis que mobilizam as dimensões comunicativa e estratégica, ilocucionária e perlocucionária, de persuasão e de convencimento, do agir.

A demanda do Terceiro por imparcialidade e pela necessidade de cuidado com o Outro como interlocutor mantém uma tensão com o fato de que, desconstrutivamente, só se pode compreender o outro imperfeitamente e através da diferença. Porém, isso não significa que devamos deixar de tentar. O esforço construtivo pela busca do consenso, com uma postura de humildade, abertura e resiliência perante o fato de que a justiça é sempre por-vir, demanda a renovação do impulso conflituoso em busca de reconhecimento, impulso este que deve reflexivamente buscar se afastar do agir estratégico diante da demanda de imparcialidade do Terceiro e da obrigação de reconhecimento do Outro como interlocutor consubstanciada no patriotismo constitucional de Habermas e no traço particularista de solidariedade que configura a eticidade formal de Honneth. Em verdade, Habermas e Honneth, ainda que pareçam defender pensamentos dicotômicos, enfatizam dimensões complementares do que podemos considerar uma postura deliberativa adequada dos movimentos sociais em uma democracia constitucional.

\section{EXCURSO}

Após a exposição das 28 teses, retomemos, para concluir, uma intuição que consubstancia o espírito do escrito. Entendemos, com Derrida, ser impositivo um abrandamento das dicotomias habermasianas entre lógica/retórica e razão/não-razão. Consideramos que tais oposições precisam ser lidas de maneira congruente com o falibilismo central da teoria de Habermas, o que a perspectiva desconstrutivo-construtiva de Bankovsky nos proporciona. Em uma metalinguagem de primeiro grau, é justamente o caráter inexorável da iteratividade do exercício racional o que Derrida procura ressaltar, e, em uma metalinguagem de segundo grau, podemos dizer que foi exatamente isso o que fizemos neste trabalho quando problematizamos desconstrutivamente as propostas construtivas de Habermas e Honneth e as correlatas dicotomias razão/sentimento, moral/ética, agir comunicativo/agir estratégico e consenso/conflito (lembrando que o ataque às oposições binárias do logocentrismo é um dos principais alvos do pensamento desconstrutivo de Derrida). Como pensa o próprio Habermas, os democratas devem ser tanto cidadãos quanto rebeldes, ou seja, devem atuar dentro dos quadros dos princípios e da cultura política democrático-constitucional. Indo mais longe, com 
Thomassen, é necessária uma expansão não apenas do próprio conteúdo positivo dos direitos humanos em uma democracia, mas também do que significam uma deliberação e uma argumentação. Em outros termos, se a razão deve responder a e pela razão, e a democracia deve responder a e pela democracia, é possível, derridarianamente, que haja uma metadeliberação sobre em que consiste deliberar. Compreendendo, com Bankovsky e com a tradição construtiva de Habermas e Honneth, o filósofo como um filósofo-cidadão, este artigo consiste em uma deliberação metalinguística, no sentido de ter como objeto a própria noção de deliberação, mormente diante da constatação de Gamson de que "a injustiça é uma cognição quente, e não um mero juízo intelectual abstrato sobre o que é equitativo" (1992, p. 32 - tradução nossa).

Recuperemos, então, a tese de Bankovsky (2012, p. 207 - tradução nossa) de que "o papel da teoria não é tanto ajustar realisticamente as nossas expectativas quanto encorajar as aspirações generosas e resilientes a realizar o impossível". Essa tese nos estimula a contribuir desconstrutivamente para a construção da tradição crítica a que estão vinculados Habermas e Honneth. Esperamos, construtivamente, lograr algum êxito neste esforço de filósofo-cidadão em provocar a autorreflexividade dos movimentos sociais; mas, desconstrutivamente, sabemos, com humildade, que o resultado de nosso esforço teórico nunca será suficiente para que alcancemos a justiça, a qual estará sempre por-vir, e preservamos nossa resiliência justamente pelo fato de sabermos que a justiça só é possível como impossível, o que mantém, desde já, o produto deste trabalho aberto a outras possibilidades desconstrutivo-construtivas.

\section{REFERÊNCIAS}

AARNIO, Aulis. Lo racional como razonable. Centro de Estudios Constitucionales, 1991. APEL, K.: "The Problem of Philosophical Foundations in Light of a Transcendental Pragmatics of Language". In: BAYNES, K. (ed.). After Philosophy. Cambridge: MIT, 1987.

BANKOVSKY, Miriam. Perfecting justice in Rawls, Habermas, Honneth. London, 2012. BENHABIB, Seyla. The right of others. Cambridge: Cambridge University Press, 2004. CALVERT, A.; WARREN, M. Can Deliberative Minipublics Overcome the Anti-Deliberative Effects of Framing? 2012 Meeting of Western Political Science Association. DERRIDA, Jacques. “A diferença”. In: Margens da filosofia. Campinas: Papirus, 1991. DOUZINAS, Costas. O fim dos direitos humanos. São Leopoldo: Unisinos, 2009. FRASER, Nancy. “Reconhecimento sem ética”. In: Lua Nova, São Paulo, n. 70, 2008. FRASER, N. Social justice in the age of identity politics. In: FRASER, N; HONNETH, A. Redistribution or recognition? New York: Verso, 2003a. GAMSON, William. Talking Politics. Cambridge: Cambridge University Press, 1992. HABERMAS, Jürgen. The theory of communicative action. Vol. I. Boston: Beacon, 1984. HABERMAS, Jürgen. On the Pragmatics of Communication. The MIT Press, 1990. HABERMAS, Jürgen. Verdade e justificação. São Paulo: Loyola, 2004. 
HEIDEGGER, Martin. Ser e tempo. Rio de Janeiro: Vozes, 2005.

HENDLEY, S.. From Communicative Action to the Face of Other. Philosophy Today, 1996.

HONNETH, Axel. A Luta por reconhecimento. São Paulo: Editora 34, 2003.

HONNETH, Axel. Disrespect. Cambridge, UK: Polity, 2008.

HONNETH, Axel. From Struggles for Recognition to a Plural Concept of Justice: An Interview with Axel Honneth. Acta Sociologica, n. 47, 2004.

LEVINAS, Emmanuel. Existence and existents. Dordrecth: Kluwer, 1978.

MARTINEAU, Samuel; KAURLOTO, John. Habermas and Social Movement. Disponível em: http://citation.allacademic.com/meta/p525273_index.html. Acesso em: mai. 2020.

PANIKKAR, Raimon. Paz e interculturalidad. Barcelona: Herder, 2006.

PERELMAN, Chaïm. Tratado da argumentação: São Paulo: Martins Fontes, 1996.

REPA, Luiz. "Contradição performativa". IN: NOBRE, Marcos. Curso livre de teoria crítica.

Campinas: Papirus, 2008, p. 295-7.

SUPREMO TRIBUNAL FEDERAL. Audiência Pública da ADPF 54-8/DF. 2008.

THOMASSEN, Lasse. Deconstructing Habermas. New York: Routledge, 2008.

YOUNG, Iris. Assymetrical reciprocity. Constellations, Vol. 3, No. 3, 1997a.

YOUNG, Iris. Justiça e a política da diferença. Princeton University Press, 1997b. 